\title{
The Pitfalls and Promise of Ecological Screening Values
}

\author{
Tamara L. Sorell ${ }^{1}$
}

Published online: 28 October 2016

(C) Springer International Publishing AG 2016

Keywords Ecological risk assessment · Screening levels · Remediation · Clean-up goals

Ecological risk assessment can be a critical part of the site remediation process, with the potential to fundamentally influence the cost and scope of site clean-up. The initial phase of an ecological risk assessment is screening, in which site contaminant concentrations are compared to published ecological screening levels (ESLs) in order to identify contaminants for further evaluation. Risk assessments in most State and Federal programs follow a process in which the identification of one or more contaminants in any sample above respective ESLs may trigger the requirement for a full baseline ecological risk assessment. Full baseline assessments are costly and time consuming, often adding months or years to the project schedule. However, many of screening levels that trigger baseline assessments are not environmentally meaningful and only serve to create unnecessary evaluation. Screening levels are also often misused at later stages of the risk process to draw inappropriate conclusions about ecological hazard. Common problems with the development and application of screening levels are described below, followed by suggestions to improve the screening and risk management processes.

Tamara L. Sorell

TSorell@brwncald.com

1 Brown and Caldwell, Two Tech Drive, Andover, MA 01810, USA

\section{Challenges with the Current Screening Levels and Their Application}

\section{ESLs Below Background}

Many ESLs for soil as well as sediment are below naturally occurring concentrations and therefore add little information about the potential for ecological risk. One example is chromium, for which Oak Ridge National Laboratory (ORNL) has recommended a soil screening level of $0.4 \mathrm{mg} / \mathrm{kg}$, about two orders of magnitude below the average and median shallow soil concentrations reported by the US Geological Survey (USGS; 36 and $30 \mathrm{mg} / \mathrm{kg}$, respectively) [1] or the US Environmental Protection Agency (EPA; 40-50 mg/kg) [2]. Any reported observation of chromium will therefore automatically "fail" screening using this ESL, and most will also exceed the EPA ecological soil screening level (EcoSSL) of $23 \mathrm{mg} / \mathrm{kg}$ [2] for avian life. Another example is manganese, which has an EcoSSL (avian life protection basis) of $220 \mathrm{mg} / \mathrm{kg}$ [3], although in the same document, EPA identifies naturally occurring background in the range of 500 to $600 \mathrm{mg} / \mathrm{kg}$, comparable to the USGS reported mean and median manganese concentrations in shallow soils (612 and $492 \mathrm{mg} / \mathrm{kg}$, respectively). Other common metals that have soil screening levels that are often below background include nickel and zinc.

\section{ESLs Used to Predict Biological Effects}

Among the most commonly applied set of screening levels are those for sediments, such as those developed by Long and Morgan [4], Persaud et al. [5], and MacDonald et al. [6] 
(whose "consensus" values are in fact geometric means of several other compendia, some with overlapping sources). These sets of ESLs were largely derived from sediment sites impacted with multiple contaminants and were developed by assuming that each individual chemical could be responsible for all observed effects. While these ESLs may have some value in identifying degraded conditions where the presence of multiple contaminants is part of a profile of overall risk, they are not useful for determining risk in specific settings or for predicting impacts linked to individual contaminants. In addition, bulk sediment concentrations are poor predictors of the bioavailable fraction of sediment contamination [7]. In a review of approaches for developing sediment ESLs, only $38 \%$ of samples with chemicals exceeding the effects range low (ERL) were actually found to be toxic [8]. Similarly, a recent study was conducted comparing the toxicity of laboratory spiked soils versus aged field collected soils concluded that total metal concentrations in field-collected soils are poor indicators of toxicity [9].

Nonetheless, risk frameworks continue to apply these ESLs stringently, using them as evidence of potential risk regardless of the number of contaminants and requiring further evaluation, often without consideration of other factors.

\section{ESLs Used to Conclude Ecological Risk}

Risks to invertebrates and plants are often identified ecological endpoints, but hazards to these receptors are not addressed in the post-screening phases with standard desktop ecological risk tools (food chain models). Bioassays to evaluate sitespecific hazards exist but are expensive and not routinely used for plants and soil invertebrates. For this reason, many ecological risk assessments erroneously use plant and invertebrate ESLs, such as the ORNL values, to calculate hazards in the risk characterization portion of the risk process. Sediment ESLs may also get used in this fashion. When the same benchmarks have already been used earlier in the risk process, this approach becomes circular and uninformative. More importantly, using conservative screening levels as indicators of hazard results in false conclusions of risk.

\section{ESLs Used as Clean-up Goals}

Most agencies and risk practitioners recognize that screening levels were not developed as clean-up goals. However, in practice, there are often no ecologically based remedial standards, and site-specific risk-based concentrations can be complicated to develop and more difficult to defend than published levels. There is therefore a natural tendency to want to reference existing peer-reviewed concentrations in the risk management process. Thus, risk managers may default to screening levels as generic clean-up goals in the absence of risk-based concentrations. For example, New Jersey
Department of Environmental Protection requires that its published list of ESLs be used as clean-up objectives for site-related contaminants unless ecological risk-based concentrations have been developed. Many of these ESLs are unrealistically low, such as, for example, the soil manganese concentration of $220 \mathrm{mg} / \mathrm{kg}$ discussed above. As a result of using ESLs as clean-up levels, a remedial decision could be made based on an unreasonably low clean-up level.

\section{Toward a More Effective Framework}

Screening is an essential component of the risk process. Done strategically, it avoids unnecessary evaluation and focuses any necessary risk assessment on key parameters. However, comparison of maximum observed concentrations to ESLs that are very low or poorly correlated with biological effects offers little predictive value. The following strategies may be useful in streamlining the ecological risk assessment process.

\section{ESLs Below Background}

The development of screening levels that are below naturally occurring background reflects flaws in the derivation methodology. Derivation should be flexible and represent the state of the science. Sediment ESLs date from studies in the 1980s and have not been updated in decades. Empirical studies from sites and the literature can provide meaningful updates. For example, the Massachusetts Department of Environmental Protection (MassDEP), after a review of 10 years of ecological risk studies state wide, determined that most sediment metal benchmarks were overly conservative and increased them several fold [10]. Other characteristics that could be introduced include soil properties such as aging. Existing chemical measurements that reflect bioavailability (such as equilibrium partitioning) should be given more weight than bulk concentrations in the screening process. Studies that address ecological effects associated with specific contaminants or are based on exposures to soils collected from sites (not spiked) would be particularly useful. For example, Checkai et al. [11] recently published an approach for deriving soil clean-up criteria for metals or metalloids that incorporates consideration of sitespecific bioavailability of weathered soils.

\section{ESLs Used to Predict Biological Effects}

Improved derivation processes may result in screening levels that are more reflective of potential biological effects. In addition, screening should be a weight-of-evidence process that considers not only published ESLs but also setting, background, number of contaminants, the ecological system, and other indictors of biological sensitivity. Over-reliance on ESLs 
and use of only maximum observed concentrations distorts the screening process and eliminates professional judgment. The risk assessor should have the flexibility to evaluate the background and basis of each ESL along with its concentration relative to background in determining whether it is appropriate for use in predicting effects in a particular setting. A more flexible screening approach would streamline the ecological risk assessment process, but would require some adjustment of programs modeled on EPA's Superfund guidance [12], which disallows site-specific considerations until the risk management process (after completion of the full baseline risk assessment).

\section{ESLs Used to Conclude Ecological Risk}

ESLs are for use in the initial phase of the risk process. They should not be re-used in risk characterization and should not serve as default clean-up goals. As an example, the Texas Commission on Environmental Quality (TCEQ) recommends using plant and invertebrate ESLs solely for the purpose of focusing the list of contaminants of potential concern, not for risk characterization nor for clean-up levels [13]

\section{ESLs Used as Clean-up Goals}

Screening levels may get applied as clean-up goals because there are no other published values to consider. There are a few examples of formal clean-up standards for ecological endpoints (such as marine sediment standards in the State of Washington [14] and Brownfield cleanup site soil standards in New York [15]). In most cases, however, the only available benchmarks are ESLs. The development of standards is complex and ecological systems in particular are variable and present additional challenges. However, the same is true to some extent of standards based on human health, which are widely promulgated. Having available clean-up goals (ideally as points of departure) in the remediation process would prevent the defaulting to ESLs that occurs in the absence of other sets of values. Ideally, such goals would be tiered to recognize different settings (nonurban, urban, industrial).

Chemical concentration screening is an important initial step in the ecological risk screening process. However, ESLs should reflect actual contamination (not background) and be applied in combination with other factors. Increased availability of published ecological-based clean-up goals would pre- vent some of the misuse of ESLs and provide a framework for consideration of ecological risk in site clean-up.

\section{Compliance with Ethical Standards}

Conflict of Interest There is no conflict of interest.

\section{References}

1. Smith et al. Major- and trace-element concentrations in soils from two continental-scale transects of the United States and Canada. Open-File Report 2005-1253. U.S. Department of the Interior, U.S. Geological Survey. 2005.

2. EPA. Ecological soil screening levels for chromium. Interim final. OSWER Directive. 2008;9285:7-66.

3. EPA. Ecological soil screening levels for manganese. Interim final. OSWER Directive. 2007;9285:7-71.

4. Long E, Morgan L. The potential for biological effects of sedimentsorbed contaminants tested in the National Status and Trends Program. NOAA Technical Memorandum NOS OMA 52. 1990.

5. Persaud D, Jaagumagi R, Hayton A. Guidelines for the protection and management of aquatic sediment quality in Ontario. Ontario Ministry of Environment and Energy. 1993. ISBN 0-7778-9248-7.

6. MacDonald D, Ingersoll C, Berger T. Development and evaluation of consensus-based sediment quality guidelines for freshwater ecosystems. Arch Environ Contam Toxicol. 2000;39:20-31. doi: $10.1007 / \mathrm{s} 002440010075$.

7. ITRC. Incorporating bioavailability considerations into the evaluation of contaminated sediment sites. The Interstate Technology \& Regulatory Council Contaminated Sediments Team. CS-1. 2011.

8. O'Connor $\mathrm{T}$ et al. Comparisons of sediment toxicity with predictions based on chemical guidelines. Environ Toxicol Chem. 1998:17:468-71.

9. Smolders E et al. Toxicity of trace metals in soil as affected by soil type and aging after contamination: using calibrated bioavailability models to set ecological soil standards. Environ Toxicol Chem. 2009;28:1633-42.

10. MassDEP. Revised sediment screening values. Update to: Section 9 of Guidance for Disposal Site Risk Characterization - In Support of the Massachusetts Contingency Plan (1996). 2006.

11. Checkai $\mathrm{R}$ et al. Deriving site-specific clean-up criteria to protect ecological receptors (plants and soil invertebrates) exposed to metal or metalloid soil contaminants via the direct contact exposure pathway. Integr. Environ Assess Manag. 2006;346-57.

12. EPA. Ecological risk assessment guidance for superfund: process for designing and conducting ecological risk assessments. Interim final. EPA 540-R-97-006. OSWER. 2007;9285:7-25.

13. TCEQ. Guidance for conducting ecological risk assessments at remediation sites in Texas. December 2001 RG-263 (revised January, 2014). 2001.

14. W.A.C. 173-204-562 and W.A.C. 173-204-563.

15. 6 NYCRR Part 375-6.6. 